\title{
Anticorpos contra vírus em galinhas de terreiro do Estado do Rio Grande do Sul, Brasil
}

\author{
Antibodies against avian viruses in backyard poultry from the Rio Grande do Sul State, Brazil
}

\author{
Helton Fernandes dos Santos ${ }^{\mathrm{I}}$ Luciane Teresinha Lovato ${ }^{\mathrm{II}}$ Maristela Lovato Flôres ${ }^{\mathrm{III}}$ \\ Iara Maria Trevisol ${ }^{\mathrm{IV}}$ Ketty Cristina Mazzuttiv ${ }^{\mathrm{V}}$ Kleitton Adolfo Pan $^{\mathrm{V}}$
}

\section{RESUMO}

No Brasil, a população de aves conhecida como galinhas de terreiro encontra-se fora do sistema de biosseguridade aplicada às criações comerciais. Para investigar a presença de anticorpos contra alguns vírus específicos nesta população, foram coletadas amostras de sangue de 867 aves não-vacinadas em 60 propriedades de 22 municípios do Estado do Rio Grande do Sul, Brasil. O soro foi testado para a presença de anticorpos contra o vírus da bronquite infecciosa das galinhas (IBV), reovírus aviário (ARV) e o vírus da doença infecciosa da bolsa (IBDV) pela técnica de soroneutralização. Anticorpos contra IBV foram detectados em 65\% (564/867) das amostras, contra ARV em 21,6\% (187/ 867) e contra IBDV em 80,2\% (695/867) das aves. Todas as propriedades avaliadas apresentavam uma ave positiva para anticorpos contra IBV e IBDV e $88,3 \%$ delas eram positivas para ARV. Os resultados demonstram que esses vírus estão presentes em galinhas de terreiro nas criações avícolas nãoindustriais da região central do Estado. Os resultados indicam a necessidade de um programa de vigilância permanente nessa população e ainda indicam a necessidade de avaliar o impacto destas infecções nos próprios plantéis e o risco associado à transmissão destas às criações comerciais.

Palavras-chave: $I B V, A R V, I B D V$, epidemiologia, ocorrência, galinhas de terreiro.

\section{ABSTRACT}

The backyard poultry are not included in the biosecurity system applied in commercial flocks in Brazil. To

\begin{abstract}
investigate the presence of antibodies to specific viral pathogens in this population, blood samples were collected from 867 non-vaccinated birds, from 60 flocks in 22 counties of the Rio Grande do Sul State, Brazil. The samples were tested to detect antibodies against infectious bronchitis virus (IBV), avian reovirus (ARV) and infectious bursal disease virus (IBDV), through the virus neutralization test. Antibodies to IBV were detected in 65\% (564/867), against ARV in $21.6 \%$ (187/867), and against IBDV in $80.2 \%$ (695/867) of the samples. All the flocks had chickens positive to IBV and IBDV antibodies, and 88.3\% of them harbored antibodies to ARV. The results show the presence of these viruses in backyard poultry from the central region of the State. It also indicates the need for additional studies aimed to evaluate the real importance of these infections for this type of flocks.
\end{abstract}

Key words: $I B V, A R V, I B D V$, epidemiology, occurrence, backyard poultry.

\section{INTRODUÇÃO}

O Brasil é o segundo maior produtor de frangos do mundo e o primeiro em exportação de carnes (UBA, 2006). Medidas de vigilância e defesa sanitária estão sendo adotadas pelo Ministério da Agricultura Pecuária e Abastecimento (MAPA) e pela indústria para manter um bom status sanitário. Apesar do controle sanitário exercido sobre as aves criadas

\footnotetext{
'Programa de Pós-graduação em Medicina Veterinária, Universidade Federal de Santa Maria (UFSM), Santa Maria, RS, Brasil.

IIDepartamento de Microbiologia e Parasitologia (DMP), Centro de Ciências da Saúde (CCS), UFSM, 97105-900, Santa Maria, RS, Brasil. E-mail: llovato@smail.ufsm.br. Fone/Fax: 55-3220 8034. Autor para correspondência.

IIIDepartamento de Medicina Veterinária Preventiva (DMVP), Centro de Ciências Rurais (CCR), Laboratório Central de Diagnóstico de Patologias Aviárias (LCDPA), UFSM, Santa Maria, RS, Brasil.

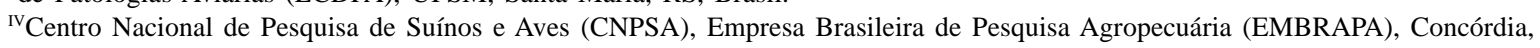
SC, Brasil.

vDepartamento de Produção Animal, Secretaria da Agricultura, Pecuária e Agronegócio, Divisão de Fiscalização e Defesa Sanitária Animal, Porto Alegre, RS, Brasil.
} 
comercialmente, algumas doenças infecciosas continuam presentes e ainda há uma população de aves que está fora deste controle. Esta população é constituída de aves que são criadas para consumo próprio, comercialização local, combate ou para prática de ritual religioso, sendo estas aves oficialmente denominadas de "galinhas de terreiro" (MAPA, 2007), e também conhecidas como galinha de fundo de quintal.

O conhecimento da ocorrência e da distribuição das infecções virais em galinhas de terreiro pode ter grande utilidade para indicar a necessidade de medidas de controle e prevenção. Patógenos virais importantes em criações comerciais, como o vírus da bronquite infecciosa das galinhas (IBV), o reovírus aviário (ARV) e o vírus da doença infecciosa da bolsa (IBDV) são mantidos sob controle por medidas de biosseguridade e pelo uso de vacinação em criações comerciais (CAVANAGH \& NAQI, 2003; LUKERT \& SAIF, 2003).

O vírus da bronquite infecciosa (IBV) é um coronavírus que causa uma enfermidade aguda e altamente contagiosa em galinhas, afetando de forma mais acentuada o sistema respiratório e urogenital (CAVANAGH \& NAQI, 2003). A ocorrência da doença foi relatada no Brasil já na década de 50 (HIPÓLITO et al., 1957) e diversos estudos têm demonstrado a sua presença em várias regiões (BRENTANO et al., 2005). A epidemiologia do IBV é complicada pela existência de vários sorotipos que podem apresentar reação sorológica cruzada, mas não apresentar proteção cruzada (IGNJATOVIC \& SAPATS, 2000; CAVANAGH \& NAQI, 2003). As diferenças entre os sorotipos de IBV devem-se a variações na seqüência de aminoácidos de duas regiões na subunidade $S_{1}$, chamadas regiões hipervariáveis. Pequenas diferenças na composição de nucleotídeos ocorrem devido à circulação do vírus na população, podendo originar novos sorotipos (COOK et al., 1997).

O reovírus aviário (ARV) é um vírus RNA, membro do gênero Orthoreovirus, importante patógeno para as aves, que causa grandes perdas econômicas na avicultura industrial (ROSENBERGER et al., 1989). Os ARVs causam primariamente artrite e tenossinovite em galinhas (KIBENGE \& WILCOX, 1983), mas podem também induzir outros quadros clínicos respiratórios e digestivos. As reoviroses aviárias apresentam distribuição mundial, sendo relatados casos em galinhas criadas comercialmente, perus, gansos e outras aves (GEORGIEVA \& JAMBAZOVA, 2003).

A infecção pelo vírus da doença infecciosa da bolsa também é descrita em todo o mundo causando perdas econômicas consideráveis (VAN DER BERG, 2000). O IBDV é um vírus RNA, classificado no gênero Avibirnavirus da família Birnaviridae (NIBERT \& SCHIFF, 2001). O vírus tem um marcante tropismo pelo tecido linfóide, causando lesões principalmente na bursa de aves jovens e levando a manifestações clínicas de diarréia, desidratação, desuniformidade e retardo no crescimento. São reconhecidos mundialmente dois sorotipos deste vírus, sendo que os patogênicos estão classificados dentro do sorotipo 1 (LUKERT \& SAIF, 2003). Diferentes cepas do sorotipo 1 já foram identificadas, entre elas uma cepa muito virulenta conhecida no Brasil como cepa hipervirulenta (DI FABIO et al., 1999; LUKERT \& SAIF, 2003). Esta variedade de cepas dentro do mesmo sorotipo dificulta o controle da doença (LUKERT \& SAIF, 2003). As cepas hipervirulentas causam lesões típicas da doença e são antigenicamente similares às cepas clássicas (JACKWOOD et al., 1987). No Brasil, alguns relatos clínico-patológicos e sorológicos indicam a presença de infecções com cepas hipervirulentas na população avícola (DI FABIO et al., 1999).

Este estudo teve como objetivo investigar a presença e a distribuição de anticorpos contra o IBV, ARV e IBDV na população de galinhas de terreiro de municípios do Estado do Rio Grande do Sul, Brasil. O estudo também avalia o papel desta população como possível reservatório de patógenos, podendo causar grandes perdas econômicas para a avicultura industrial.

\section{MATERIAL E MÉTODOS}

Amostragem: amostras de sangue de 867 galinhas de diferentes idades, sem histórico de vacinação contra o IBV, o ARV e o IBDV, foram coletadas em 60 propriedades de 22 municípios do Estado Rio Grande do Sul, durante o período de janeiro de 2006 a março de 2007. O sangue foi coletado da veia braquial com auxílio de seringa e permaneceu por uma hora em temperatura ambiente. Após a retração do coágulo, as amostras de sangue foram centrifugadas por 10 minutos a $1600 \mathrm{x}$ g, o soro foi coletado, inativado por 30 minutos a $56^{\circ} \mathrm{C}$, e armazenado a $-20^{\circ} \mathrm{C}$ até ser testado.

Células e vírus: para a multiplicação dos vírus e realização dos testes de soroneutralização (SN), foram utilizadas células primárias de fibroblasto de embrião de galinha (FEG) para o ARV e o IBDV, e células primárias de rim de pinto (CRP) para o IBV, cultivadas a partir de ovos livres de patógenos específicos (SPF). As células foram cultivadas em meio F10-199 Nutrient Mixture (F-10 HAM e meio 199, Sigma ${ }^{a}$ ) suplementado 
com $10 \%$ de soro fetal bovino (Cultilab ${ }^{\mathrm{b}}$ ), $5 \%$ de caldo Triptose Fosfato (TPB), antibióticos (estreptomicina $0,4 \mathrm{mg} \mathrm{ml}^{-1}$; penicilina $1,6 \mathrm{mg} \mathrm{ml}^{-1}$ ) e antifúngico (fungizona 0,0025 $\mathrm{mg} \mathrm{ml}^{-1}$ ). As cepas virais Beaudette do IBV, S1133 do ARV e GT-1 do IBDV foram cedidas pela Empresa Brasileira de Pesquisa Agropecuária Aves e Suínos (Concórdia, SC).

Soroneutralização (SN): os testes de SN para a detecção de anticorpos contra o IBV, o ARV e o IBDV, foram realizados conforme a metodologia descrita por ROMERO (1987). Resumidamente, as amostras de soro foram diluídas (1:20 até 1:2560) e incubadas com 100 a 200 doses infectantes para $50 \%$ dos cultivos celulares $\left(\right.$ DICC $_{50}$ ) das cepas do IBV, ARV ou IBDV. Após um período de incubação de $1 \mathrm{~h}$, foram adicionadas células de FEG para o ARV e o IBDV ou células de CRP para o IBV. Amostras positivas e negativas de soro foram incluídas em cada teste. Foram considerados títulos a recíproca da maior diluição do soro capaz de prevenir a produção de efeito citopático (ECP). Os testes de SN foram interpretados após 96h de incubação.

\section{RESULTADOS E DISCUSSÃO}

Neste trabalho, foram examinadas amostras de soro de 867 aves para a presença de anticorpos contra os vírus IBV, ARV e IBDV. As amostras foram coletadas de galinhas alojadas em 60 propriedades localizadas no Estado do Rio Grande do Sul. As aves coletadas são criadas fora do sistema industrial e, assim, denominadas galinhas de terreiro.

Os resultados gerais da distribuição das amostras por município e dados de positividade na SN são apresentados na tabela 1 . Na figura 1 , é demonstrada a distribuição da freqüência de título de anticorpos nas aves contra os três vírus estudados. A tabela 2 apresenta a freqüência de anticorpos de acordo com finalidade e tipo de criação.

No Brasil, o status epidemiológico das galinhas de terreiro é pouco estudado e a prevalência de anticorpos contra os vírus IBV, IBDV e ARV não é conhecida nesta população. Pesquisas realizadas em outros países demonstram alta prevalência destes vírus

Tabela 1 - Presença de anticorpos contra o vírus da bronquite infecciosa das galinhas (IBV), reovírus aviário (ARV) e vírus da doença infecciosa da bolsa (IBDV) em galinhas de terreiro não-vacinadas, de acordo com o município de coleta no Estado do Rio Grande do Sul, Brasil.

\begin{tabular}{|c|c|c|c|c|c|}
\hline \multirow{3}{*}{ Municípios } & \multirow{3}{*}{$\mathrm{n}^{\circ}$. de propriedades } & \multirow{3}{*}{$\mathrm{n}^{0}$. de amostras } & \multicolumn{3}{|c|}{ Amostras positivas $^{\mathrm{a}}$} \\
\hline & & & \multicolumn{3}{|c|}{----------------------'nº.(\%)---------------------- } \\
\hline & & & IBV & ARV & IBDV \\
\hline Agudo & 3 & 43 & $34(79,0)$ & $19(44,2)$ & $37(86,0)$ \\
\hline Capão do Leão & 2 & 44 & $30(68,2)$ & $18(40,9)$ & $34(77,3)$ \\
\hline Casca & 4 & 51 & $9(17,6)$ & $7(13,7)$ & $38(74,5)$ \\
\hline Colorado & 2 & 17 & $11(64,7)$ & $5(29,4)$ & $12(70,6)$ \\
\hline Dezesseis de Novembro & 1 & 21 & $15(71,4)$ & $9(42,9)$ & $16(76,2)$ \\
\hline Faxinal do Soturno & 2 & 21 & $14(66,7)$ & $5(23,8)$ & $19(90,5)$ \\
\hline Formigueiro & 2 & 29 & $17(58,6)$ & $5(17,2)$ & $21(72,4)$ \\
\hline Itaara & 3 & 22 & $15(68,2)$ & $4(18,2)$ & $15(68,2)$ \\
\hline Mata & 2 & 20 & $12(60,0)$ & $2(10,0)$ & $18(90,0)$ \\
\hline Não-Me-Toque & 2 & 38 & $26(68,4)$ & $9(23,7)$ & $29(76,3)$ \\
\hline Nova Palma & 3 & 49 & $32(65,3)$ & $1(2,0)$ & $37(75,5)$ \\
\hline Paraíso do Sul & 4 & 39 & $31(79,5)$ & $7(17,9)$ & $30(76,9)$ \\
\hline Pelotas & 1 & 8 & $3(37,5)$ & $0(0,0)$ & $8(100,0)$ \\
\hline Quarai & 2 & 36 & $33(91,7)$ & $12(33,3)$ & $31(81,1)$ \\
\hline Restinga Seca & 2 & 40 & $31(77,5)$ & $9(22,5)$ & $34(85,0)$ \\
\hline Santa Maria & 15 & 171 & $108(63,2)$ & $30(17,5)$ & $146(85,4)$ \\
\hline São Luiz Gonzaga & 1 & 34 & $21(61,8)$ & $13(38,2)$ & $24(70,6)$ \\
\hline São Pedro do Sul & 1 & 27 & $23(85,2)$ & $3(11,1)$ & $22(81,5)$ \\
\hline São Sepé & 2 & 23 & $15(65,2)$ & $1(4,3)$ & $15(65,2)$ \\
\hline Silveira Martins & 3 & 49 & $29(59,2)$ & $10(20,4)$ & $42(85,7)$ \\
\hline Tapera & 2 & 40 & $26(65,0)$ & $14(35,0)$ & $29(72,5)$ \\
\hline Toropi & 1 & 45 & $32(71,1)$ & $4(8,9)$ & $38(84,5)$ \\
\hline TOTAL & 60 & 867 & $567(65,0)$ & $187(21,6)$ & $695(80,2)$ \\
\hline
\end{tabular}

${ }^{\mathrm{a}}$ Foram consideradas positivas as amostras com títulos de anticorpos neutralizantes $>20$.

Ciência Rural, v.38, n.7, out, 2008. 

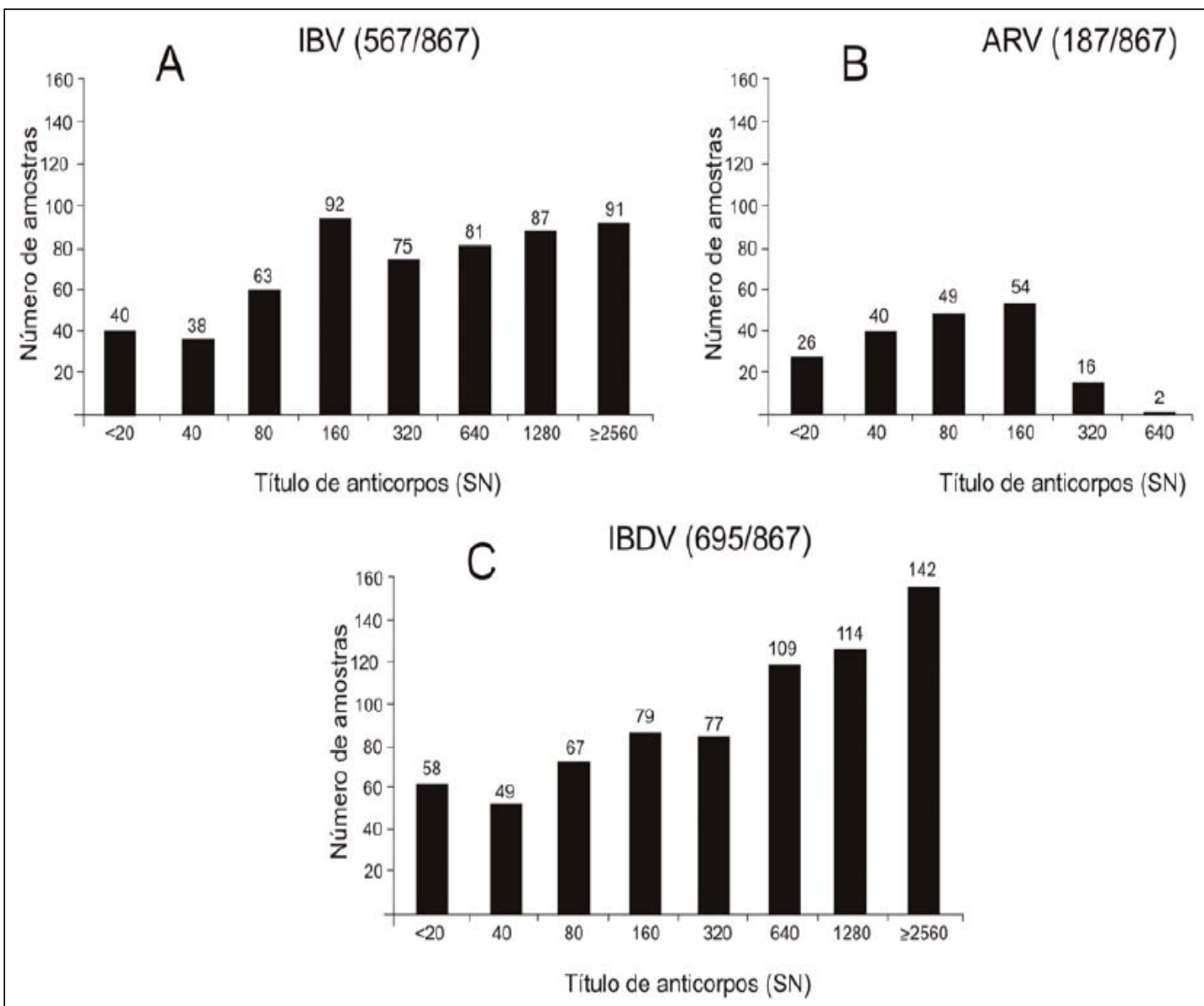

Figura 1 - Freqüência dos títulos de anticorpos contra: A. vírus da bronquite infecciosa das galinhas (IBV); B. reovírus aviário (ARV) e C. vírus da doença infecciosa da bolsa (IBDV) em galinhas de terreiro não-vacinadas do Estado do Rio Grande do Sul, Brasil. SN - soroneutralização.

em populações semelhantes. (DIVERS, 2006; OWOADE et al., 2006; VOLK, 2005).

A infecção pelo IBV está amplamente distribuída na população de aves de terreiro e a presença de anticorpos contra este vírus já foi detectada em $85 \%$ das aves pesquisadas no Equador (DIVERS, 2006) e $84 \%$ na Nigéria (OWOADE et al., 2006). Uma taxa de 43\% também foi descrita na Eslovênia (VOLK, 2005). A prevalência de $65 \%$ (Tabela 1 ) de aves com anticorpos contra o IBV demonstra uma situação semelhante àquela encontrada no México, onde 74,9\% das aves pesquisadas apresentaram anticorpos contra este vírus (RUIZ et al., 2002).

Já no caso do IBDV, a prevalência de 80,2\% (Tabela 1) das aves positivas para a presença de anticorpos é comparável a estudos feitos por VOLK (2005) na Eslovênia, em que 78\% das aves foram soropositivas, e por DIVERS (2006), no Equador, onde $100 \%$ das aves foram positivas.
O percentual de aves soropositivas para o reovírus foi relativamente baixo $(21,6 \%)$ quando comparado com os outros dois vírus estudados ou com os dados de outros países. As aves de terreiro da Nigéria e da Eslovênia apresentaram uma soropositividade mais alta sendo de $41 \%$ no primeiro caso (OWOADE et al., 2006) e de $92 \%$ no segundo (VOLK, 2005). A diferença de prevalência na comparação com os outros países provavelmente seja explicada, em parte, por diferenças epidemiológicas nas populações em estudo.

Quando foi realizada a quantificação dos títulos de anticorpos no soro (Figura 1), observou-se um grande número de amostras de soro com altos títulos de anticorpos contra os vírus IBV e IBDV (=2560). A grande maioria das amostras examinadas contra o ARV apresentou títulos de anticorpos entre 40 e 160 . A literatura apresenta diversos dados de títulos de anticorpos para aves comerciais (COOK et al., 1997; 
Tabela 2 - Presença de anticorpos contra o vírus da bronquite infecciosa das galinhas (IBV), reovírus aviário (ARV) e vírus da doença infecciosa da bolsa (IBDV) em galinhas de terreiro não-vacinadas de municípios do RS, Brasil, de acordo com a finalidade e o tipo de criação.

\begin{tabular}{|c|c|c|c|c|c|c|c|}
\hline \multirow{3}{*}{ Vírus } & \multicolumn{4}{|c|}{-------------------------Finalidade da criação------------------------- } & \multicolumn{3}{|c|}{-----------------Tipo de criação-----------------’ } \\
\hline & consumo próprio & religião & raças combatentes & outros & confinada & semiconfinada & vida livre \\
\hline & $\mathrm{n}=744$ & $n=36$ & $\mathrm{n}=57$ & $\mathrm{n}=30$ & $\mathrm{n}=104$ & $n=248$ & $\mathrm{n}=515$ \\
\hline IBV & 65,7 & 66,7 & 61,4 & 63,3 & 55,8 & 63,3 & 68,3 \\
\hline ARV & 22,6 & 11,1 & 12,3 & 26,7 & 18,3 & 17,7 & 24,0 \\
\hline IBDV & 80,6 & 80,6 & 71,9 & 83,3 & 69,2 & 83,9 & 80,6 \\
\hline
\end{tabular}

JACKWOOD et al., 1987), mas não foram encontrados parâmetros para comparação com o tipo de ave estudada no presente trabalho. Além disso, os dados encontrados na literatura registram valores de títulos de anticorpos gerados em resposta à vacina e não à infecção natural.

As altas taxas de amostras positivas contra o IBV e o IBDV indicam que estes vírus infectaram mais de dois terços da população estudada. Este dado, aliado aos altos títulos de anticorpos observados em uma boa parcela destas aves, reforça a idéia de que estes vírus circulam amplamente na população de galinhas de terreiro da região. Esta circulação pode ser considerada um risco à sanidade avícola, considerandose a capacidade de disseminação destes agentes infecciosos (COOK et al., 1997; ETERRADOSSI et al., 2000; CAVANAGH \& NAQI, 2003).

Apenas 6,8\% das aves pesquisadas foram negativas para anticorpos contra todos os vírus testados. Quando os dados foram cruzados, observouse que $12,7 \%$ apresentaram anticorpos contra os três agentes pesquisados e $61,4 \%$ apresentaram anticorpos para mais de um agente. Entre estas, 86,6\% apresentaram anticorpos contra os vírus de IBV e IBDV concomitantemente. As características destes agentes, como a via de transmissão e a sua resistência no ambiente, podem ter contribuído para esta alta prevalência (LUKERT \& SAIF, 2003; IGNJATOVIC \& SAPATS, 2000).

Em todas as propriedades pesquisadas, foram encontradas aves positivas contra IBV e IBDV, sendo que $88,3 \%$ das propriedades possuíam aves soro-positivas para o ARV. O fato de um grande número de propriedades apresentar pelo menos uma ave positiva ilustra a permanência ou à circulação periódica destes patógenos nas criações estudadas. Como já observado por BUCHALA et al. (2006), a elevada frequiência de criatórios com aves sororeagentes indica risco de introdução, em aves de exploração comercial, de agentes de doenças transmissíveis que se encontram distribuídos na natureza.
A população pesquisada foi composta de aves de corte e postura para consumo próprio, aves destinadas a ritual religioso, aves de rinhas (raças combatentes) e outras. Em função do desconhecimento do número total ou aproximado destas populações, a coleta das amostras foi realizada sem um delineamento estatístico. Isso explica, pelo menos em parte, a disparidade no número de amostras em cada uma das categorias.

As aves soropositivas classificadas conforme a finalidade da criação, como as de consumo próprio ou comércio local, apresentaram uma prevalência de 65,7\% (IBV), 22,6\% (ARV) e 80,6\% para o IBDV, e as raças combatentes, de $61,4 \%$ para IBV, 12,3\% para o ARV e 71,9\% para o IBDV. Esses índices são preocupantes devido à ausência de biosseguridade entre essas criações. A movimentação destas aves é um grande fator de risco, principalmente nas raças combatentes, para as quais pode ocorrer trânsito sem nenhum controle sanitário.

As aves criadas semiconfinadas ou livres apresentaram taxas mais altas de soropositividade para o IBV e IBDV que as aves criadas em sistema de confinamento, o que pode refletir a maior exposição das aves de vida livre aos patógenos considerados. O fácil acesso dessas aves a outras espécies de animais que podem servir de carreadores mecânicos do agente talvez possa ser uma das razões da diferença observada (GARBER et al., 2007).

\section{CONCLUSÕES}

Os dados demonstram que os vírus IBV, IBDV e ARV estão circulando na população de galinhas de terreiro do Estado do Rio Grande do Sul. É importante salientar que estes patógenos são responsáveis por enfermidades que causam grandes prejuízos econômicos na avicultura comercial e que a contínua circulação destes vírus em aves de terreiro pode facilitar o surgimento de cepas com maior patogenicidade. O conhecimento da epidemiologia destes vírus em aves 
de terreiro é fundamental para o planejamento de estratégias de controle nestas populações e conseqüente disseminação para as criações comerciais.

\section{AGRADECIMENTOS}

Os autores agradecem à Fundação de Amparo à Pesquisa do Estado do Rio Grande do Sul (FAPERGS), pelo financiamento, à equipe de virologia aviária da EMBRAPA, pelo material e auxílio técnico; à Cooperativa Languiru Ltda., pelo apoio. À Coordenação de Aperfeiçoamento de Pessoal de Nível Superior (CAPES), pela concessão de bolsa ao primeiro autor, e ao Setor de Virologia da UFSM.

\section{FONTES DE AQUISIÇÃO}

aSigma Chemical Company Po Box 14508, St. Louis/USA. ${ }^{\mathrm{b} C}$ ultilab LTDA, Campinas, SP, Brasil.

\section{REFERÊNCIAS}

BRENTANO, L. et al. Isolamento do vírus da bronquite infecciosa das aves de surtos da doença associada a lesões atípicas de miopatia peitoral. In: CONFERÊNCIA APINCO DE CIÊNCIA E TECNOLOGIA AVÍCOLAS, 2005, Santos, SP. Anais... Santos: Fundação Apinco de Ciência e Tecnologia Avícolas (FACTA), 2005. Suplemento 7, p.232.

BUCHALA, F. G. et al. Detecção de resposta sorológica contra Mycoplasma em aves de criatórios de "fundo de quintal" próximos a explorações comerciais do Estado de São Paulo. Arquivos do Instituto Biológico, v.73, n.2, p.143-148, 2006.

CAVANAGH, D.; NAQI, S.A. Infectious bronchitis. In: CALNEK, B.W. et al. Diseases of poultry. Ames: Iowa State Press, 2003. Cap.3, p.101-119.

COOK, J.K.A. et al. Breadth of protection of the respiratory tract provided by different live-attenuated infectious bronchitis vaccines against challenge with infectious bronchitis viruses of heterogonous serotypes. Avian Pathology, v.28, p.477-485, 1997.

DI FABIO, J. et al. Very virulent IBD spreads to South America. World Poultry Journal, v.15, p.88-91, 1999.

DIVERS, S.M.H. A survey of selected avian pathogens of backyard poultry in northwestern Ecuador. Journal of Avian Medicine and Surgery, v.20, p.147-158, 2006.

ETERRADOSSI. N. et al. Comparison of European and SouthAmerican strains of very virulent infectious bursal disease viruses. Actualization Avicola de Amevea, v.1, p.15-30, 2000.

GARBER, L. et al. Non-commercial poultry industries: surveys of backyard and gamefowl breeder flocks in the United States. Preventive Veterinary Medicine, v.80, p.120-128, 2007.

GEORGIEVA, M.V.; JAMBAZOVA, N. Serological surveys on broiler breeder flocks for antibodies against chicken infectious anaemia virus and avian reoviruses. Institute of Experimental Pathology and Parasitology, v.40, n.6, p.84-86, 2003.

HIPÓLITO, O. et al. Isolamento e identificação do vírus da bronquite infecciosa em galinhas no Brasil. Arquivo da Escola de Veterinária UFMG, v.10, p.131-135, 1957.

IGNJATOVIC J.; SAPATS S. Avian infectious bronchitis virus. Revue Scientifique Et Technique, v.19, n.2, p.493-508, 2000.

JACKWOOD, D.J. et al. IBDV: molecular differentiation of antigenic subtypes among serotype 1 viruses. Avian Diseases, v.38, p.531-537, 1987.

KIBENGE, F.S.B.; WILCOX, G.E. Tenosynovitis in chickens. Veterinary Bulletin, v.53, n.2, p.431-443, 1983.

LUKERT, P.D.; SAIF, Y.M. Infectious bursal disease. In: CALNEK, B.W. et al. Diseases of poultry. Ames: Iowa State Press, 2003. Cap.6, p.161-179.

MAPA, Ministério da Agricultura, Pecuária e Abastecimento. Brasília, 2007. Capturado em 15 de abr. 2007. On-line. Disponível na Internet: http:// www.agricultura.gov.br/pnsa.html

NIBERT, M.L.; SCHIFF, L.A. Reoviruses and their replication. In: KNIPE, D.M.; HOWLEY, P.M. Fields virology. Philadelphia: Lippincott - Raven publishers, 2001. p.16791728.

OWOADE A.A. et al. Seroprevalence of avian influenza virus, infectious bronchitis virus, reovirus, avian pneumovirus, infectious laryngotracheitis virus and avian leukosis virus in Nigerian poultry. A vian Diseases, v.50, p.222-227, 2006.

ROMERO, C.H. Manual de técnicas virológicas e sorológicas para o isolamento e identificação de vírus aviários e seus anticorpos. Concórdia: Embrapa- Centro Nacional de Pesquisa de Suínos e Aves, 1987. 65p.

ROSENBERGER, J.K. et al. Pathogenicity and antigenic relatedness of several avian reovirus isolates: in vitro and in vivo characterization of avian reoviruses. Avian Diseases, v.33, p.535-544, 1989.

RUIZ, E.J.G. et al. A serological survey for avian infectious bronchitis virus and Newcastle disease virus antibodies in backyard (free-range) village chickens in Mexico. Tropical Animal Health and Production, v.32, p.381-390, 2002.

UBA, União Brasileira de Avicultores, relatório anual 2004 - 2005. Brasília: Charbel, 2006, 87p. (Boletim Técnico).

VAN DER BERG, T.P. Acute infectious bursal disease in poultry: a review. Avian Pathology, v.29, n.1, p.175-194, 2000.

VOLK, M. Health status of backyard flocks in Slovenia - some preliminary data. Institute for Poultry Health, v.11, p.47, 2005. 